\title{
Association of Endodontic Involvement with Tooth Loss in the Veterans Affairs Dental Longitudinal Study
}

\author{
Dr. Yan Zhong, DMD, PhD, \\ program of Oral Epidemiology, University of North Carolina, Chapel Hill, NC.
}

Dr. Raul Garcia, DMD, MMSc,

VA Boston Healthcare System and the Henry M. Goldman School of Dental Medicine, Boston University, Boston, MA.

\section{Dr. Elizabeth K Kaye, PhD, MPH,}

VA Boston Healthcare System and the Henry M. Goldman School of Dental Medicine, Boston University, Boston, MA.

\author{
Dr. Jianwen Cai, PhD[Professor], \\ Department of Biostatistics, School of Public Health, University of North Carolina, Chapel Hill, \\ NC. \\ Dr. Jay S Kaufman, PhD, \\ School of Public Health, University of North Carolina, Chapel Hill, NC, and now is with \\ Department of Epidemiology, Biostatistics, and Occupational Health, McGill University, Canada. \\ Dr. Martin Trope, DMD[Professor], \\ Department of Endodontics, School of Dentistry, University of North Carolina, Chapel Hill, NC. \\ Dr. Tim Wilcosky, PhD, and \\ School of Public Health, University of North Carolina, Chapel Hill, NC.

\section{Dr. Daniel J Caplan, DDS, PhD[Professor and Chair]} \\ Department of Preventive \& Community Dentistry, College of Dentistry, University of lowa, lowa \\ City, IA.
}

\section{Abstract}

\begin{abstract}
Introduction-The effect of endodontic involvement on tooth loss has not been quantified, so the present study aimed to assess this relationship after controlling for other relevant risk factors for tooth loss.
\end{abstract}

\begin{abstract}
Methods-We analyzed data from 791 participants (18,798 teeth) in the Veterans Affairs Dental Longitudinal Study. Potential tooth- and person-level covariates were fitted into marginal proportional hazards models, including both apical radiolucencies (AR) and root canal therapy (RCT) status as time-dependent variables. Survival curves were plotted for teeth according to their AR and RCT status.
\end{abstract}

\footnotetext{
(C) 2010 American Association of Endodontics. Published by Elsevier Inc. All rights reserved. Dr. Zhong is the corresponding author..

Publisher's Disclaimer: This is a PDF file of an unedited manuscript that has been accepted for publication. As a service to our customers we are providing this early version of the manuscript. The manuscript will undergo copyediting, typesetting, and review of the resulting proof before it is published in its final citable form. Please note that during the production process errors may be discovered which could affect the content, and all legal disclaimers that apply to the journal pertain.
} 
Results-Both current AR and RCT status were associated with increased risk of tooth loss ( $\mathrm{p}<$ 0.01), after controlling for baseline levels of periodontal disease, caries, tooth type, number of proximal contacts, number of teeth, age, education, and smoking history. Root canal filled (RCF) teeth seemed to have better survival than non-RCF teeth among teeth with AR, but worse survival than non-RCF teeth among teeth without AR.

Conclusions-Endodontic involvement was associated with tooth loss, controlling for other potential risk factors. Additional prospective studies are needed to provide better evidence as to the impact of endodontic involvement on tooth loss.

\section{Keywords}

Apical radiolucency; endodontics; epidemiology; root canal therapy; survival analysis; tooth loss

Tooth loss results from a combination of factors, including periodontal disease and caries (1-3), tooth type (1,4-6), number of teeth at baseline (7), age (7-9), education level $(9,10)$, gender $(7,8)$, income $(8,11)$, race $(8)$, oral hygiene behaviors $(6,12)$, and smoking $(3,9,13)$. Tooth loss due to periodontal disease also is reported to be associated with diabetes, hypertension, and rheumatoid arthritis (6). Endodontically treated teeth are at risk for loss due to additional mechanisms; factors related to loss of root-canal filled (RCF) teeth include absence of crown (14-17), number of proximal contacts $(18,19)$, incomplete root canal therapy (RCT) (20), quality of root fillings $(1,21)$, and use of posts $(1,14,17)$.

The role of endodontic involvement (e.g., periapical inflammation, RCT) in tooth loss has not been examined extensively. In previous studies, RCF teeth were lost significantly more often than teeth without RCT $(1,22,23)$, and periapical lesions have been found to be related to a higher risk of tooth loss $(1,17)$. Despite these observational findings, periapical lesions often are not defined as a specific cause for tooth loss, but rather as a sequel to dental caries. Some studies have mentioned "failed endodontic treatment" or "pain" as causes of extraction without explicitly recognizing periapical lesions (24); others used RCT only as an indicator of pulpal involvement (23), but RCT is not warranted for all endodontically involved teeth (e.g., teeth with hopeless periodontal status), and RCT sometimes is performed on non-endodontically involved teeth. Thus, it is advisable to evaluate periapical inflammation and RCT as two distinct factors when studying the impact of endodontic involvement on tooth loss.

Gaps in the relevant literature include the following: First, in general, these studies do not account for correlations among teeth within the same individual in their analytic approaches; doing so would avoid incorrect inferences in hypothesis testing $(25,26)$. Second, conventional analytic methods used in tooth loss studies such as logistic or linear regression cannot accommodate common features existing in survival data such as timing of events, censoring, and time-dependent covariates (TDC) $(27,28)$. Rather than simply discarding information on censored teeth, survival analysis uses all the information up to the time the tooth is censored, and thus is a preferable analytic approach. Third, periapical status often has not been considered, or has been combined with caries, as related to tooth loss; little has been done to evaluate its role as a separate factor in tooth loss. Finally, no data are available to evaluate the effect of RCT on tooth loss after adjusting for periapical conditions on individual teeth.

The purpose of the present study was to investigate the association of endodontic involvement with tooth loss, after controlling for other tooth- and person-level risk factors for tooth loss at baseline (our hypothesis was that both RCT and periapical lesion status would be associated with tooth loss). 


\section{MATERIALS AND METHODS}

\section{Study population}

Data analyzed in this study were from the Veterans Affairs Dental Longitudinal Study (VADLS), an ongoing, closed-panel longitudinal study of oral health and disease among 1,231 adult males aged 25-85 years at baseline in the 1960's. The cohort was established through community-based recruitment of adult men from the greater Boston metropolitan area. Participants were not patients of the VA system; rather, they received dental and medical care through the private sectors.

One goal of the VADLS is to identify determinants of oral health in an aging population. Participants had varying oral conditions at baseline, though all were free of chronic medical conditions. Since baseline, study participants have been seen once every 3 years for comprehensive dental and medical examinations. Dental examinations include both clinical and radiographic components. The clinical component was conducted by a trained and calibrated VADLS periodontist examiner. Data collected included decayed, missing or filled coronal tooth surfaces (DMFS) and detailed measures of periodontal status. The radiographic component includes a full mouth series of intra-oral radiographs (29).

To date, this cohort has been under observation for over 30 years. The average interval between VADLS exams has been approximately 38 months and there were about 200 men who had a cycle 11 examination (corresponding to 30 years after baseline) by January 2004 (3). The present study used the electronic VADLS database to identify participants who were dentate at baseline, all of whom had a complete radiographic record for each of the 32 permanent teeth or tooth spaces at baseline and each subsequent examination cycle. Due to time considerations, the sample size was restricted to 853 randomly selected participants. The protocol for this study was reviewed and approved by the Institutional Review Board on Research Involving Human Subjects at the VA Boston Healthcare System.

\section{Follow-up period}

Our analysis includes all teeth present at baseline, regardless of whether or not they were endodontically involved. For each tooth, follow-up started at the subject's baseline cycle and ended when the tooth was lost or the date of most recent examination prior to data collection, whichever came first.

\section{Data collection}

Tooth- and person-level covariates were obtained from the VADLS data set, while variables describing endodontic status and treatment were made solely from available radiographs of diagnostic quality. Two second-year endodontic residents from Boston University independently reviewed subjects' intra-oral radiographs. Before data collection, a training and calibration session for the radiographic examiners was conducted to assure adequate reliability and to evaluate diagnostic criteria for endodontic measurements. Kappa values describing inter-examiner reliability were excellent for the endodontic variables, ranging from $0.80-1.00$, depending on the variable (30). Diagnostic criteria for radiographic evaluation of endodontic variables (described below) were adapted from Odesjo et al (31).

\section{Endodontic variables}

At each examination cycle, endodontic involvement was assessed according to the following two variables: 1) "RCT status", i.e., whether or not the tooth had RCT; and 2) "Apical Radiolucency (AR) status", which was categorized into 3 levels based on the size of periapical rarefaction: no AR (i.e., apical periodontal ligament space $<1 \mathrm{~mm}$ thick), 1-3 $\mathrm{mm}$, and $\leq 4 \mathrm{~mm}$. AR was used as a general indicator of periapical inflammation due to the 
established correlation between AR and histologically confirmed inflammatory status of the periapical tissues (32). For a tooth with RCT at baseline, the tooth would remain "RCT=yes" throughout the rest of its life; whereas for a tooth without RCT at baseline, the tooth could become "RCT=yes" at any cycle after baseline. Additionally, because growth and healing of periapical lesions are dynamic processes, a tooth's AR status could vary within 3 levels during the follow-up regardless of its AR value at baseline, e.g., an existing AR could resolve or worsen, or a new AR could develop. To describe endodontic variables in more accurate detail, both RCT and AR status were treated as TDCs in the analysis. Their timedependent values were incorporated with the partial likelihood methods adopted in survival analysis $(27,33)$. Additional variables related to each tooth's RCT included whether or not RCT was complete (yes/no); extension and density of root fillings (34); type of filling material; number of posts; and year of RCT. These RCT treatment-related variables were considered as TDC as well because they only applied to teeth with RCT (33). Other RCTrelated variables (e.g., perforation, broken instruments) were not included in the analysis due to too few events having occurred.

\section{Covariates}

A large number of tooth- and person-level variables were available from the parent VADLS data set. Baseline tooth-level covariates included whether a tooth had an existing crown (yes/no), tooth type (anterior/premolar/molar), number of proximal contacts (i.e., either 0, 1, or 2 adjacent teeth), coronal caries (yes/no), and periodontal status (i.e., alveolar bone loss, gingival bleeding, mobility, plaque score, and probing pocket depth). Except for crowns, there were no data to indicate other types of overlay restorations. Baseline person-level covariates included number of teeth, patient age, income, education, race, smoking history, diabetes, hypertension, body mass index, and oral hygiene behaviors (i.e., frequency of brushing, flossing, history of periodontal treatment, and history of cleaning).

\section{Statistical analyses}

The tooth was the unit of analysis. Statistical analyses were performed in three stages: (1) univariate description of data using frequencies and percentages; (2) bivariate associations between each covariate individually and tooth loss, and tests of survival differences among subgroups of each covariate using the log-rank test and Cox-type models; and (3) multivariable marginal proportional hazards models (extended Cox-type regression models for correlated survival data) to evaluate joint associations of tooth loss with various factors (25). Time to tooth loss was the dependent variable, with current RCT and AR status as the explanatory variables of main interest in the full model. We were interested in studying the association of current endodontic involvement with tooth loss after adjusting for baseline covariates. Current RCT and AR status are approximated by the status obtained at the beginning of that cycle. The adjustment is to ensure that the other covariates (i.e., potential confounders) were balanced at the beginning of the follow-up. For example, the interpretation for the estimated coefficient for RCT is the log hazard ratio of tooth loss for comparing the tooth that currently has RCT with the tooth that currently has no RCT, assuming that current AR status is the same and that the other covariates are balanced at baseline.

Marginal proportional hazards models with time-dependent endodontic variables (extended Cox models) were used to assess the effects of the endodontic involvement on time to tooth loss. All risk factors initially were put into the full model regardless of their p-values in the bivariate analysis. Starting by eliminating variables with the largest p-values, backward selection was used to identify significant risk factors, and only those with p-values $<0.05$ were retained in the final model. No interaction terms were tested. Adjusted hazard ratios and the corresponding 95\% confidence intervals (CI) were computed for each retained 
variable in the model. Once the final model was obtained, the adequacy of the model was assessed to make sure the correct functional form of the explanatory variables had been used and the proportional hazards ( $\mathrm{PH}$ ) assumption was met for each variable in the final model. Plots of $\log (-\log$ (survival function)) versus time for categorical variables and plots of Schoenfeld residuals for continuous variables were used to verify the PH assumption, respectively (28).

After the final model was generated, to illustrate the differences in survival curves for teeth with different patterns of endodontic involvement, tooth survival curves were plotted based on a stratified model with current AR and RCT status as the strata and adjusting for the same set of the baseline covariates as in the final multivariable regression model (28). All statistical tests were two-tailed and performed with SAS Version 9.1 (SAS Institute Inc, Cary, NC).

\section{RESULTS}

The 853 randomly selected participants accounted for 27,296 teeth or tooth spaces, but the current analysis included only 18,798 teeth from 791 participants (Figure 1). Follow-up time ranged from 0.9 to 33.0 years, and of the 18,798 teeth, 2,589 (13.8\%, from 541 participants) were lost during follow-up (Table 1). Basic characteristics of the study population at baseline are described in Table 2. At baseline, only 293 teeth (1.6\%) had received RCT and 137 teeth $(0.7 \%)$ had AR. The mean age of participants at baseline was 48 years-of-age, with a range of 28-84 years.

Bivariate analyses revealed that the presence of RCT or AR was associated with a significantly increased hazard of tooth loss. Moreover, significantly increased hazard ratios were observed for all subgroups of baseline covariates shown in Table 2 except for: interproximal plaque with continuation on buccal or lingual surface, brushing $\geq 2$ times per day, any periodontal treatment, African-American participants, body mass index of $25-<30$ $\mathrm{kg} / \mathrm{m}^{2}$, former smokers, diabetes, and hypertension ( $\left.\mathrm{p}>0.05\right)$.

In the final multivariable regression model (Table 3), both RCT and AR status remained as significant risk factors for time to tooth loss $(\mathrm{p}<0.05)$, after controlling for significant baseline covariates. At any given time, the hazard of loss for a tooth that had current RCT was $1.39(95 \%$ CI: $1.10,1.74)$ times that of a tooth without current RCT, controlling for other factors in the model; and compared to teeth without current AR, hazard ratios (95\% CI) of tooth loss were $6.95(5.44,8.88)$ for teeth with current AR of $\geq 4 \mathrm{~mm}$ and 4.11 (2.80, 6.03) for teeth with current AR of 1-3 mm, respectively, controlling for other factors in the model. Results from the assessment of $\mathrm{PH}$ assumption showed that the $\mathrm{PH}$ assumption was satisfied for all variables that remained in the final model.

In the multivariable analysis, a significantly higher hazard of tooth loss also was observed among molars, teeth with fewer proximal contacts or with coronal caries at baseline, participants with fewer teeth at baseline, older age, lower education level, or smoking history at baseline. Additionally, teeth with more alveolar bone loss, gingival bleeding, mobility or deeper probing pocket at baseline had significantly higher hazards of tooth loss. Covariates evaluated but not retained in the final model due to non-significance included oral hygiene behaviors, RCT treatment-related variables (i.e., whether or not RCT was complete, extension and density of root fillings, type of filling material, number of posts, and year of RCT), presence of crown, income, race, diabetes, hypertension, and body mass index.

Finally, survival curves reflecting tooth loss by different patterns of AR and RCT status over time are shown in Figures 2 and 3. These plots are based on a stratified model with different 
combinations of current AR and RCT status as the strata and adjusted for the same set of the baseline covariates as in the above final multivariable regression model. The stratified model is fitted using all the 18,798 teeth from the 791 participants. Note that the survival probability depends on the pattern of AR and RCT status over time and therefore, for a tooth with a particular pattern of AR and RCT status over time, the survival probability can be calculated based on the estimated regression coefficients from the above fitted stratified model and the specified pattern of AR and RCT. Specifically, Figure 2A presents the survival probability for teeth that had no AR. The two curves are for teeth that had no RCT and had RCT, respectively. For example, the 10-year survival probability for teeth that had no AR and no RCT during this 10 -year period is about 0.97 , while the 10 -year survival probability for teeth that had no AR but had RCT is about 0.95 . The curves suggest that, among teeth that had no AR lesions, teeth with RCT seemed to have worse survival than those without RCT (Figure 2A); whereas among teeth which had AR of $1-3 \mathrm{~mm}$ or $\geq 4 \mathrm{~mm}$, teeth with RCT seemed to have better survival than those without RCT after about 8 years of follow-up (Figures $2 \mathrm{~B}$ and $2 \mathrm{C}$ ). Figure $3 \mathrm{~A}$ presents the survival probability for teeth that had no RCT. The three curves are for teeth that had no AR, had AR of 1-3mm, and had AR $\geq$ $4 \mathrm{~mm}$, respectively. For example, the 10-year survival probability for teeth that had no RCT and no AR during the 10-year period is about 0.97. Similarly, the 10-year survival probability for teeth that had no RCT but had AR of 1-3mm during the 10-year period is about 0.84 . Figures $3 \mathrm{~A}$ and $3 \mathrm{~B}$ suggest that regardless of teeth had RCT or not, those teeth without AR seemed to have substantially better survival than teeth with AR of 1-3 $\mathrm{mm}$ or $\geq$ $4 \mathrm{~mm}$.

\section{DISCUSSION}

Our findings confirm that tooth loss is a complex process involving both tooth-level and person-level covariates $(2,8,18)$ and also lend credence to our hypothesis that, after controlling for other relevant risk factors, variables indicating current endodontic involvement would remain significantly and independently associated with tooth loss. Although RCF teeth have been reported to be lost more readily than non-RCF teeth $(1,22,23)$, previous studies rarely differentiated the survival of RCF teeth between those with and without AR, so we analyzed AR and RCT as two distinct variables in the current study and further evaluated the survival curves of RCF and non-RCF teeth based on their AR status. Among teeth without AR, those that had RCT seemed to have worse survival than those that had no RCT, possibly because RCF teeth in general have more structural damage than non-RCF teeth, which could hasten their loss. Conversely, among teeth with AR, those that had RCT seemed to have better survival than those that had no RCT, suggesting that RCT for teeth with inflamed periapical tissues can help prolong their survival (Figure 2) (15).

Our results agree with previous studies in that teeth with AR had worse survival than teeth without AR $(1,17,35)$, and it makes intuitive sense that teeth with a compromised periapical status would have a higher hazard of loss. One new result is that the greater the AR size, the worse the tooth survival for RCF teeth (35). Additionally, survival curves seemed to be further apart between teeth with and without AR among teeth that had no RCT than the corresponding curves among teeth that had RCT (Figure 3), suggesting that AR is not as strongly associated with tooth loss when RCT is present. Readers should be cautioned that the survival curves presented here were obtained using an observational study design that could not evaluate whether RCT would improve tooth survival for teeth with given characteristics; that question would be better addressed using a randomized controlled trial design. 
Besides endodontic involvement, our study had some interesting findings of some immutable baseline covariates (e.g., tooth type, the number of proximal contacts, and the number of teeth at baseline) that we feel noteworthy of discussing. We present them as follows. Molars had greater hazard of loss than anterior teeth and premolars, consistent with previous studies $(1,4,5)$ and specifically studies of RCF teeth $(17,19,21)$. Due to their complex anatomy and compromised accessibility, molars are more difficult to clean and develop caries more often than other teeth; and subsequent periodontal and endodontic problems in molars are more difficult to treat as well. Molars also likely are extracted more frequently than other teeth due to non-functionality or being in a non-aesthetic area. In addition, our results confirm previous findings of associations between baseline proximal contacts (adjacent teeth) and tooth loss in RCF teeth $(18,19)$ and extend these results to nonRCF teeth. Adjacent teeth help distribute occlusal forces over a wider span, thus reducing the load borne by any individual tooth (18). The adjusted hazard ratio for number of baseline proximal contacts in our study is less than that reported before, which might be because previous studies analyzed the number of proximal contacts at the start of RCT when assessing the loss of RCF teeth, whereas the present study used the baseline value for that variable when assessing subsequent tooth loss after baseline. Prior tooth loss has been reported to predict future tooth loss $(7,8,10,18)$, and our results regarding the number of teeth remaining at baseline are consistent with this finding. Our results also agree with previous studies in that older age and lower education level at baseline were associated with subsequent tooth loss $(3,7-9,18)$. Participants with a lower education level likely place less value on maintaining their dental hygiene and saving their teeth, or have more financial limitations than others with higher education.

Any epidemiologic investigation has limitations, and this study was no exception. The present study was limited by the availability and completeness of existing documentation, and some potentially important variables related to dental care providers were not collected because participants in the parent VADLS data set were not VA patients and received dental care from their private dentists, who were not contacted in conjunction with the study. Only males were included in the present sample, hence the findings might only be applicable to men. Evaluation of overlay restorations was limited to the variable "presence of crown", and assessment of endodontic variables was based on radiographs only, so no clinical evaluation of pulpal or periapical health could be conducted.

To our knowledge, this is the first report to concurrently study the association between endodontic involvement (as evidenced by AR and/or RCT) and tooth loss with 30 years of data, while adjusting for important risk factors for tooth loss. However, it is important to recognize that determination of whether RCT can prolong tooth survival can only be properly assessed by comparison of endodontically involved teeth for which RCT is indicated. More longitudinal studies would be desirable to further investigate the effect of RCT on teeth with pulpal involvement.

In summary: Regarding potential factors related to tooth loss, indicators of endodontic involvement have not received as much attention as have indicators of periodontal disease and caries. The present longitudinal study found that endodontic involvement (as assessed by current AR and RCT status in a time-dependent fashion) was significantly associated with tooth loss, and this association was independent of the baseline effects of other potential risk factors available in the dataset. If endodontic involvement ultimately is shown consistently to be associated with subsequent tooth loss, especially in longitudinal studies that ascertain main exposure variables and potential confounders as precisely as possible, that would present stronger evidence that endodontically involved teeth are more likely to be lost sooner than teeth without endodontic involvement. Additional prospective studies are needed to provide better evidence as to the impact of endodontic involvement on tooth loss. 


\section{Acknowledgments}

The authors thank Drs. Jeffrey Hutter, Joel Chasen, Ryan Yamanaka, and John Stamm, without whose assistance this study would not have been possible. The VA Dental Longitudinal Study and the VA Normative Aging Study are components of the Massachusetts Veterans Epidemiology Research \& Information Center, VA Boston Healthcare System, Boston, MA. The studies are supported by the VA Cooperative Studies Program/ERIC, U.S. Department of Veterans Affairs. Dr. Garcia was the recipient of a Career Development Award in Health Services Research from VA HSR\&D Service. He is supported by a VA Epidemiology Merit Review Award and by NIH grant K24-DE00419 from the National Institute of Dental and Craniofacial Research. Dr. Cai is supported by NIH grant UL1 RR025747. The study was also supported by NIDCR Grants R01 DE013807, R03 DE017948, and R03 DE016357.

The authors deny any financial affiliations related to this study or its sponsors.

\section{REFERENCES}

1. Eckerbom M, Magnusson T, Martinsson T. Reasons for and incidence of tooth mortality in a Swedish population. Endod Dent Traumatol 1992;8(6):230-4. [PubMed: 1302686]

2. Burt, B.; Eklund, S. Dentistry, dental practice, and the community. 5th ed. W. B. Saunders Co.; Philadelphia: 1999. p. 203-211.

3. Krall EA, Garvey AJ, Garcia RI. Alveolar bone loss and tooth loss in male cigar and pipe smokers. J Am Dent Assoc 1999;130(1):57-64. [PubMed: 9919032]

4. Marcus SE, Drury TF, Brown LJ, Zion GR. Tooth retention and tooth loss in the permanent dentition of adults: United States, 1988-1991. J Dent Res 1996;75 Spec No:684-95. [PubMed: 8594092]

5. Hujoel PP, Loe H, Anerud A, Boysen H, Leroux BG. Forty-five-year tooth survival probabilities among men in Oslo, Norway. J Dent Res 1998;77(12):2020-7. [PubMed: 9839791]

6. Al-Shammari KF, Al-Khabbaz AK, Al-Ansari JM, Neiva R, Wang HL. Risk indicators for tooth loss due to periodontal disease. J Periodontol 2005;76(11):1910-8. [PubMed: 16274310]

7. Eklund SA, Burt BA. Risk factors for total tooth loss in the United States; longitudinal analysis of national data. J Public Health Dent 1994;54(1):5-14. [PubMed: 8164192]

8. Gilbert GH, Miller MK, Duncan RP, et al. Tooth-specific and person-level predictors of 24-month tooth loss among older adults. Community Dent Oral Epidemiol 1999;27(5):372-85. [PubMed: 10503798]

9. Leung WK, Ng DK, Jin L, Corbet EF. Tooth loss in treated periodontitis patients responsible for their supportive care arrangements. J Clin Periodontol 2006;33(4):265-75. [PubMed: 16553635]

10. Burt BA, Ismail AI, Morrison EC, Beltran ED. Risk factors for tooth loss over a 28 -year period. J Dent Res 1990;69(5):1126-30. [PubMed: 2335645]

11. Lin HC, Corbet EF, Lo EC, Zhang HG. Tooth loss, occluding pairs, and prosthetic status of Chinese adults. J Dent Res 2001;80(5):1491-5. [PubMed: 11437226]

12. Vysniauskaite S, Kammona N, Vehkalahti MM. Number of teeth in relation to oral health behaviour in dentate elderly patients in Lithuania. Gerodontology 2005;22(1):44-51. [PubMed: 15747898]

13. Krall EA, Dawson-Hughes B, Garvey AJ, Garcia RI. Smoking, smoking cessation, and tooth loss. J Dent Res 1997;76(10):1653-9. [PubMed: 9326897]

14. Vire DE. Failure of endodontically treated teeth: classification and evaluation. J Endod 1991;17(7): 338-42. [PubMed: 1779219]

15. Lazarski MP, Walker WA 3rd, Flores CM, Schindler WG, Hargreaves KM. Epidemiological evaluation of the outcomes of nonsurgical root canal treatment in a large cohort of insured dental patients. J Endod 2001;27(12):791-6. [PubMed: 11771594]

16. Aquilino SA, Caplan DJ. Relationship between crown placement and the survival of endodontically treated teeth. J Prosthet Dent 2002;87(3):256-63. [PubMed: 11941351]

17. Cheung GS, Chan TK. Long-term survival of primary root canal treatment carried out in a dental teaching hospital. Int Endod J 2003;36(2):117-28. [PubMed: 12657155] 
18. Caplan DJ, Weintraub JA. Factors related to loss of root canal filled teeth. J Public Health Dent 1997;57(1):31-9. [PubMed: 9150061]

19. Caplan DJ, Kolker J, Rivera EM, Walton RE. Relationship between number of proximal contacts and survival of root canal treated teeth. Int Endod J 2002;35(2):193-9. [PubMed: 11843976]

20. Caplan DJ, White BA. Clinical factors related to noncompletion of root canal therapy. J Public Health Dent 2001;61(1):6-13. [PubMed: 11317604]

21. Cheung GS. Survival of first-time nonsurgical root canal treatment performed in a dental teaching hospital. Oral Surg Oral Med Oral Pathol Oral Radiol Endod 2002;93(5):596-604. [PubMed: 12075211]

22. Jaoui L, Machtou P, Ouhayoun JP. Long-term evaluation of endodontic and periodontal treatment. Int Endod J 1995;28(5):249-54. [PubMed: 8626207]

23. Caplan DJ, Cai J, Yin G, White BA. Root canal filled versus non-root canal filled teeth: a retrospective comparison of survival times. J Public Health Dent 2005;65(2):90-6. [PubMed: 15929546]

24. Eriksen, H. Epidemiology of apical periodontitis. In: Orstavik, D.; Ford, T Pitt, editors. Essential endodontology. Prevention and treatment of apical periodontitis. Blackwell Science Ltd; Oxford: 1998. p. 184-185.

25. Lee, E.; Wei, L.; Amato, D. Cox-type regression analysis for large numbers of small groups of correlated failure time observations. In: Klein, J.; Goel, P., editors. Survival analysis: state of the art. Kluwer; Dordrecht: 1992. p. 237-247.

26. Caplan DJ, Slade GD, Gansky SA. Complex sampling: implications for data analysis. J Public Health Dent 1999;59(1):52-9. [PubMed: 11396045]

27. Allison, P. Survival analysis using SAS: a practical guide. SAS Institute Inc.; Cary, NC: 1995.

28. Collett, D. Texts in statistical science. 2nd ed. Chapman \& Hall/CRC CRC Press LLC; Florida: 2003. Modelling survival data in medical research.

29. Garcia RI, Krall EA, Vokonas PS. Periodontal disease and mortality from all causes in the VA Dental Longitudinal Study. Ann Periodontol 1998;3(1):339-49. [PubMed: 9722718]

30. Landis JR, Koch GG. The measurement of observer agreement for categorical data. Biometrics 1977;33(1):159-74. [PubMed: 843571]

31. Odesjo B, Hellden L, Salonen L, Langeland K. Prevalence of previous endodontic treatment, technical standard and occurrence of periapical lesions in a randomly selected adult, general population. Endod Dent Traumatol 1990;6(6):265-72. [PubMed: 2094601]

32. Orstavik D, Kerekes K, Eriksen HM. The periapical index: a scoring system for radiographic assessment of apical periodontitis. Endod Dent Traumatol 1986;2(1):20-34. [PubMed: 3457698]

33. Kleinbaum, D. Survival analysis: a self-learning text. Springer-Verlag Inc.; New York: 1995.

34. Zhong Y, Chasen J, Yamanaka R, et al. Extension and density of root fillings and postoperative apical radiolucencies in the veterans affairs dental longitudinal study. J Endod 2008;34(7):798803. [PubMed: 18570982]

35. Chugal NM, Clive JM, Spangberg LS. A prognostic model for assessment of the outcome of endodontic treatment: Effect of biologic and diagnostic variables. Oral Surg Oral Med Oral Pathol Oral Radiol Endod 2001;91(3):342-52. [PubMed: 11250634] 


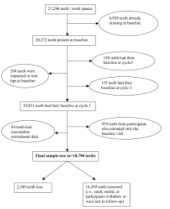

Figure 1.

Description of Study Sample 


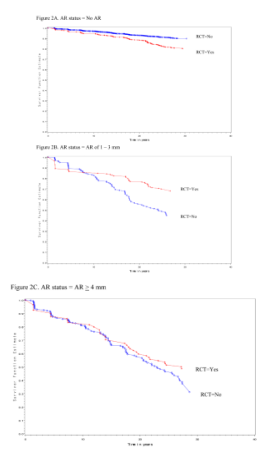

Figure 2.

Survival curves by RCT status, plotted by AR status and at the mean values of the other baseline covariates. 
Figure $3 \mathrm{~A}$. RCT status $=$ No RCT

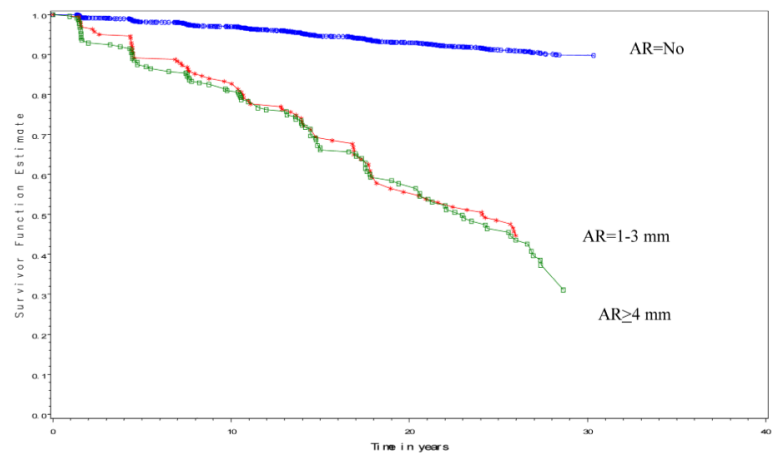

Figure 3B. RCT status $=$ Had RCT

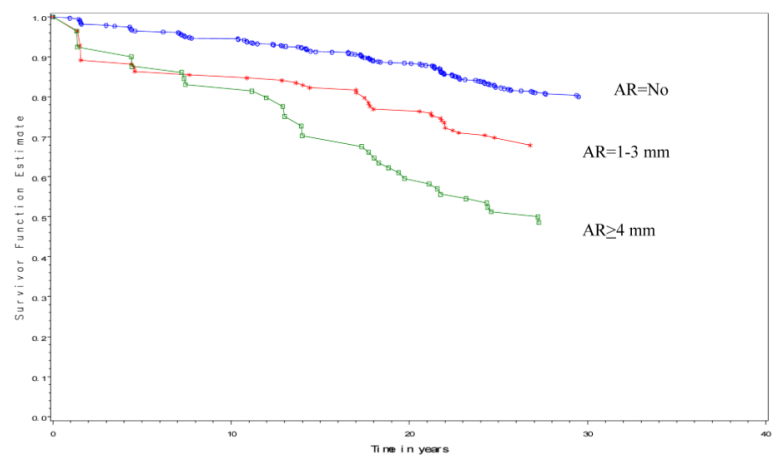

Figure 3.

Survival curves by AR status, plotted by RCT status and at the mean values of the other baseline covariates. 


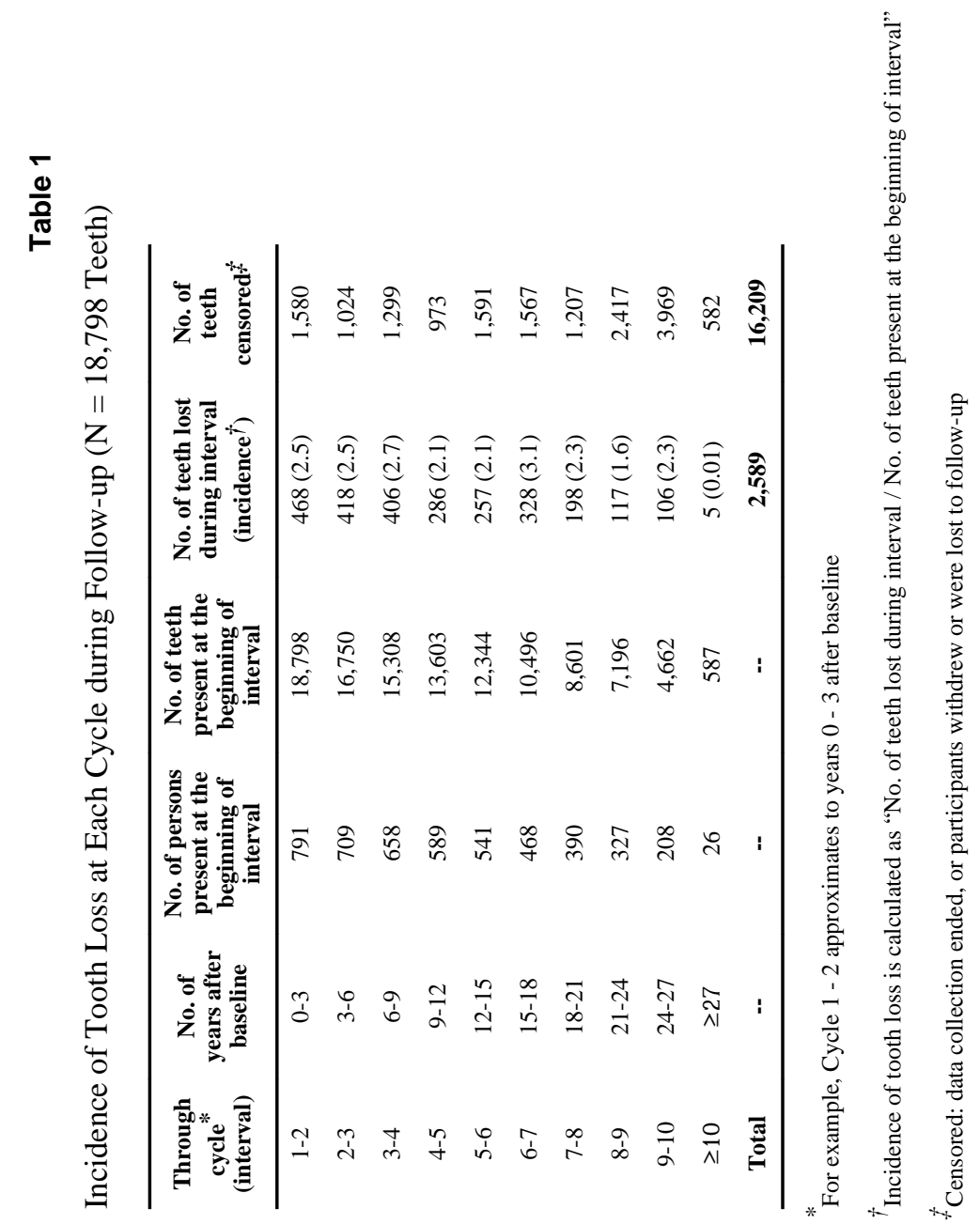


Table 2

Univariate Distribution of Baseline Study Variables ( $\mathrm{N}=18,798$ teeth)

\begin{tabular}{|c|c|c|c|c|}
\hline \multicolumn{2}{|l|}{ Variable } & Level & Frequency & Percent (\%) \\
\hline \multicolumn{5}{|l|}{ Outcome } \\
\hline \multirow{2}{*}{\multicolumn{2}{|c|}{ Tooth loss }} & Yes & 2589 & 13.8 \\
\hline & & No & 16,209 & 86.2 \\
\hline \multicolumn{5}{|c|}{ Endodontic involvement } \\
\hline \multirow{2}{*}{\multicolumn{2}{|c|}{ RCT status }} & Yes & 293 & 1.6 \\
\hline & & No & 18,505 & 98.4 \\
\hline \multirow{3}{*}{\multicolumn{2}{|c|}{ AR status }} & $\geq 4 \mathrm{~mm}$ & 73 & 0.4 \\
\hline & & $1-3 \mathrm{~mm}$ & 64 & 0.3 \\
\hline & & No & 18,661 & 99.3 \\
\hline \multicolumn{5}{|c|}{ Tooth-level covariates } \\
\hline \multirow{2}{*}{\multicolumn{2}{|c|}{ Crown }} & Yes & 759 & 4.0 \\
\hline & & No & 18,039 & 96.0 \\
\hline \multirow{3}{*}{\multicolumn{2}{|c|}{ Tooth Type }} & Molar & 5,070 & 27.0 \\
\hline & & Premolar & 5,053 & 26.9 \\
\hline & & Anterior & 8,675 & 46.2 \\
\hline \multirow{3}{*}{\multicolumn{2}{|c|}{ No. of proximal contacts }} & 0 & 939 & 5.0 \\
\hline & & 1 & 4,798 & 25.5 \\
\hline & & 2 & 13,061 & 69.5 \\
\hline \multirow{2}{*}{\multicolumn{2}{|c|}{ Coronal caries* }} & Yes & 3,547 & 18.9 \\
\hline & & No & 14,271 & 75.9 \\
\hline \multirow{13}{*}{$\begin{array}{l}\text { Periodontal } \\
\text { status* }\end{array}$} & \multirow{3}{*}{$\begin{array}{l}\text { Alveolar bone } \\
\text { loss }\end{array}$} & $\geq 20 \%$ & 2,203 & 11.7 \\
\hline & & $<20 \%$ & 6,454 & 34.3 \\
\hline & & None & 9,827 & 52.3 \\
\hline & \multirow{2}{*}{$\begin{array}{l}\text { Gingival } \\
\text { bleeding }\end{array}$} & Yes & 11,572 & 61.6 \\
\hline & & No & 7,032 & 37.4 \\
\hline & \multirow[t]{2}{*}{ Mobility } & Yes & 1,994 & 10.6 \\
\hline & & No & 16,610 & 88.4 \\
\hline & \multirow{4}{*}{ Plaque score } & All surfaces with $2 / 3$ of tooth & 2,350 & 12.5 \\
\hline & & $\begin{array}{l}\text { Interproximal with continuation } \\
\text { on buccal or lingual surface }\end{array}$ & 8,008 & 42.6 \\
\hline & & Interproximal only & 5,811 & 30.9 \\
\hline & & None & 2,435 & 13.0 \\
\hline & \multirow{2}{*}{$\begin{array}{l}\text { Probing pocket } \\
\text { depth }\end{array}$} & $>3 \mathrm{~mm}$ & 3,008 & 16.0 \\
\hline & & $\leq 3 \mathrm{~mm}$ & 15,596 & 83.0 \\
\hline
\end{tabular}




\begin{tabular}{|c|c|c|c|c|}
\hline \multicolumn{2}{|l|}{ Variable } & Level & Frequency & Percent $(\%)$ \\
\hline \multicolumn{5}{|c|}{ Person-level covariates } \\
\hline \multirow{8}{*}{$\begin{array}{l}\text { Oral } \\
\text { hygiene } \\
\text { behaviors }\end{array}$} & \multirow{2}{*}{$\begin{array}{l}\text { Frequency of } \\
\text { brushing }\end{array}$} & $\geq 2$ times per day & 8,049 & 42.8 \\
\hline & & $<2$ times per day & 10,701 & 56.9 \\
\hline & \multirow[t]{2}{*}{ Use floss } & Yes & 6,923 & 36.8 \\
\hline & & No & 11,850 & 63.0 \\
\hline & \multirow{2}{*}{$\begin{array}{l}\text { Any perio } \\
\text { treatment }\end{array}$} & Yes & 1,624 & 8.6 \\
\hline & & No & 17,149 & 91.2 \\
\hline & \multirow[t]{2}{*}{ Any cleaning } & Yes & 15,891 & 84.5 \\
\hline & & No & 2,882 & 15.3 \\
\hline \multirow{3}{*}{\multicolumn{2}{|c|}{ No. of teeth at baseline }} & $\leq 17$ & 890 & 4.7 \\
\hline & & $18-25$ & 7,423 & 39.5 \\
\hline & & $26-32$ & 10,485 & 55.8 \\
\hline \multirow{3}{*}{\multicolumn{2}{|c|}{ Age at baseline (years old) }} & $\geq 65$ & 537 & 2.9 \\
\hline & & $55-<65$ & 3,170 & 16.9 \\
\hline & & $<55$ & 15,091 & 80.3 \\
\hline \multirow{2}{*}{\multicolumn{2}{|c|}{ Income ${ }^{*}$}} & $>\$ 25,000$ & 6,716 & 35.7 \\
\hline & & $\leq \$ 25,000$ & 11,738 & 62.4 \\
\hline \multirow{3}{*}{\multicolumn{2}{|c|}{ Education }} & High school or less & 5,577 & 29.7 \\
\hline & & Some college & 6,961 & 37.0 \\
\hline & & College graduate & 6,260 & 33.3 \\
\hline \multirow{2}{*}{\multicolumn{2}{|c|}{ Race }} & African-American & 441 & 2.4 \\
\hline & & White & 18,357 & 97.7 \\
\hline \multirow{3}{*}{\multicolumn{2}{|c|}{ Body mass index ${ }^{*}$}} & $\geq 30 \mathrm{~kg} / \mathrm{m}^{2}$ & 1,692 & 9.0 \\
\hline & & $25-<30 \mathrm{~kg} / \mathrm{m}^{2}$ & 10,137 & 53.9 \\
\hline & & $<25 \mathrm{~kg} / \mathrm{m}^{2}$ & 6,941 & 36.9 \\
\hline \multirow{3}{*}{\multicolumn{2}{|c|}{ Smoking history }} & Current smoker & 7,822 & 41.6 \\
\hline & & Former smoker & 5,945 & 31.6 \\
\hline & & Never smoker & 5,031 & 26.8 \\
\hline \multirow{2}{*}{\multicolumn{2}{|c|}{ Diabetes }} & Yes & 562 & 3.0 \\
\hline & & No & 18,236 & 97.0 \\
\hline \multirow{2}{*}{\multicolumn{2}{|c|}{ Hypertension }} & Yes & 2,779 & 14.8 \\
\hline & & No & 16,019 & 85.2 \\
\hline
\end{tabular}

J Endod. Author manuscript; available in PMC 2011 December 1. 
Table 3

Multivariable Marginal Proportional Hazards Model of Tooth Loss ( $\mathrm{N}=18,798$ Teeth)

\begin{tabular}{|c|c|c|c|}
\hline Independent variable & Level & P-value & $\begin{array}{l}\text { Hazard ratio } \\
(95 \% \text { CI })^{\dagger}\end{array}$ \\
\hline \multicolumn{4}{|c|}{ Endodontic involvement (Time-dependent, tooth-level variables) } \\
\hline \multirow[t]{2}{*}{ RCT status } & Yes & 0.005 & $1.39(1.10,1.74)$ \\
\hline & No ${ }^{*}$ & & \\
\hline \multirow[t]{3}{*}{ AR status } & $\geq 4 \mathrm{~mm}$ & $<0.0001$ & $6.95(5.44,8.88)$ \\
\hline & $1-3 \mathrm{~mm}$ & $<0.0001$ & $4.11(2.80,6.03)$ \\
\hline & No* & & \\
\hline \multicolumn{4}{|l|}{ Tooth-level covariates } \\
\hline \multirow[t]{3}{*}{ Tooth type } & Molar & $<0.0001$ & $1.65(1.35,2.01)$ \\
\hline & Premolar & 0.109 & $1.15(0.97,1.36)$ \\
\hline & Anterior* & & \\
\hline \multirow{3}{*}{$\begin{array}{l}\text { No. of proximal contacts } \\
\text { at baseline }\end{array}$} & 0 & 0.029 & $1.26(1.02,1.55)$ \\
\hline & 1 & 0.026 & $1.18(1.02,1.35)$ \\
\hline & $2^{*}$ & & \\
\hline \multicolumn{4}{|l|}{ Person-level covariates } \\
\hline No. of teeth at baseline & Continuous & $<0.0001$ & $0.94(0.92,0.96)$ \\
\hline Age at baseline (years old) & Continuous & 0.017 & $1.02(1.00,1.03)$ \\
\hline \multirow[t]{3}{*}{ Education at baseline } & High school or less & $<0.0001$ & $1.75(1.35,2.27)$ \\
\hline & Some college & 0.010 & $1.37(1.08,1.74)$ \\
\hline & College graduate ${ }^{*}$ & & \\
\hline
\end{tabular}

